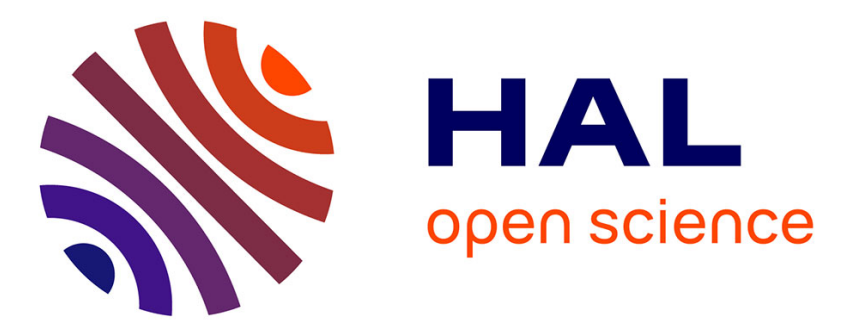

\title{
Occurrence and numerical prediction of surface defects during flanging of metallic sheets
}

\author{
Alban Le Port, Sandrine Thuillier, Pierre-Yves Manach
}

\section{To cite this version:}

Alban Le Port, Sandrine Thuillier, Pierre-Yves Manach. Occurrence and numerical prediction of surface defects during flanging of metallic sheets. International Journal of Material Forming, 2010, 3 (3), pp.215-223. 10.1007/s12289-009-0677-4 . hal-00494122

\section{HAL Id: hal-00494122 \\ https://hal.science/hal-00494122}

Submitted on 5 Feb 2019

HAL is a multi-disciplinary open access archive for the deposit and dissemination of scientific research documents, whether they are published or not. The documents may come from teaching and research institutions in France or abroad, or from public or private research centers.
L'archive ouverte pluridisciplinaire HAL, est destinée au dépôt et à la diffusion de documents scientifiques de niveau recherche, publiés ou non, émanant des établissements d'enseignement et de recherche français ou étrangers, des laboratoires publics ou privés. 


\title{
Occurrence and numerical prediction of surface defects during flanging of metallic sheets
}

\author{
Alban Le Port • Sandrine Thuillier • \\ Pierre-Yves Manach
}

\begin{abstract}
Surface defects can develop on automotive exterior panels after drawing and flanging steps, during springback and may alter significantly the vehicle quality. These defects are characterized by a small depth below $0.5 \mathrm{~mm}$ and are then difficult to detect numerically. This study focuses on the surface defects for two parts: an industrial upper corner of a front door and a L-shaped part designed on purpose to reproduce at a small scale surface defects that occur after flanging. Dimensions of these defects are measured from profiles obtained either with a non-contacting method or a tridimensional measuring machine. Numerical simulations of the processes are performed with the commercial codes PamStamp2G or Abaqus and deformed meshes are analyzed in the same way as the experimental data. There is a good correlation between experiments and simulations concerning the spatial position of the defect and their dimensions. Moreover, a buckling analysis during springback is performed for the L-shaped part, showing that the position of the defect corresponds to one of the buckling mode.
\end{abstract}

Keywords Surface defects • Numerical simulation • Flanging $\cdot$ Metallic sheets

A. Le Port · S. Thuillier $(\bowtie) \cdot$ P.-Y. Manach Université de Bretagne-Sud, LIMATB, rue de Saint Maudé, BP 92116, 56321 Lorient, France e-mail: sandrine.thuillier@univ-ubs.fr

A. Le Port · S. Thuillier · P.-Y. Manach

Université européenne de Bretagne, Rennes, France

\section{Introduction}

The numerical design of tools in the field of thin sheet metal forming is nowadays commonly used in the automotive industry. Tool geometries and process parameters are validated through the use of criteria that mainly detect localized thinning, such as forming limit curves. But other types of defect may invalidate the process, such as wrinkles [1] or surface deflections [2]. Wrinkles classically refer to macroscopic features with a depth of the order of a few millimeters and an average size in the sheet plane of the order of a few centimeters; they occur under compressive stresses during forming [1]. Surface defects [2] or deflections [3] occur at a smaller scale, with a depth of about ten micrometers and a size of about ten millimeters; they are thought to develop during springback. Their numerical prediction is a major concern because during the first validation tests of the forming tools, these defects are not visible by the human eye and manual scratching or optical inspection using a reflecting light on the oil-covered surface is necessary to highlight them. However, after painting, these defects seriously alter the product quality. Morevover, there are no well-established guidelines to follow in order to suppress these surface defects and tedious trials have to be performed.

Surface defects occur near specific areas of automotive parts, such as doors and trunk lids, characterized by a rather small curvature, low stiffness, and a change of the geometry that is quite sharp, such as near the door handle or the fuel lid (teddy-bear ears). These defects are evidenced after the first drawing step. Another type is also observed near the upper corner of an automotive door after flanging [4]. Comparison between numerical prediction and experimental results on either a 
simplified geometry [5] or a real automotive door [2] show good correlation. The proposed method is based on the curvature measure [6] of both the experimental geometry and the numerical one, obtained within an explicit calculation with shell elements of the drawing and an implicit scheme for springback [3]. The main conclusion of these works is that numerical simulation can predict surface defect near a door handle. It should be emphasized that for all these studies, the spatial position of the defect is known from experiments and this knowledge guides the numerical analysis of the predicted surface geometry.

Hence, further work must be performed to predict the occurrence of surface defects without prior knowledge of their position, to evaluate their size and to investigate different forming stages of the process, like flanging [7]. Flanging is the last stage of a deep drawing process, consisting in bending the edge of the part at $90^{\circ}$ to its reference surface, which prepares for further assembly stages like hemming [8]. In this work, a surface defect occurring at the upper corner of an automotive door in flanging is characterized and its dimensions are measured and compared with numerical predictions. Moreover, a dedicated flanging tool has been designed to reproduce this type of surface defect on a simplified geometry. Starting from planar virgin samples, a L-shaped part made of DP500 steel is flanged over a height of $4 \mathrm{~mm}$. Numerical simulation of this process is presented with the finite element code Abaqus, within an explicit framework and evolution of the flanging load, as well as defect dimensions are compared with experimental ones.

\section{Experimental investigation}

In this study, two geometries are considered and presented below: an industrial automotive door obtained after drawing, trimming and flanging and an initially planar L-shaped part, designed on purpose, to be representative of the first one.

\section{Industrial part}

An experimental surface defect on the upper corner of the door made of mild forming steel has been observed and measured. This defect (Fig. 1) appears after the flanging operation when the blank is released from the die during springback. One easy method to observe a surface defect is to set a long-flat object such as a steel ruler on the blank outer surface (Fig. 1c) which is normally a convex surface. A gap between the surface and the steel ruler highlights the presence of a depression on the initially convex surface. The blank surface can be scratched with a wheatstone and the depression is highlighted by the unscratched area (Fig. 1a). Another rapid yet only qualitative method consists in observing the oil-covered surface in a neon-chamber room (Fig. 1b); light reflexion is perturbated near surface defects. The severity of the defect is then ranked and marked by a specialist. Nevertheless, these markings are user-dependent. In the following, a quantitative method is presented.

For measurements, optical techniques have been preferred because of their simplicity of use and their
Fig. 1 Different experimental methods to highlight a surface defect. a Wheatstone scratching. b Neon chamber visualization. c Steel ruler visualization

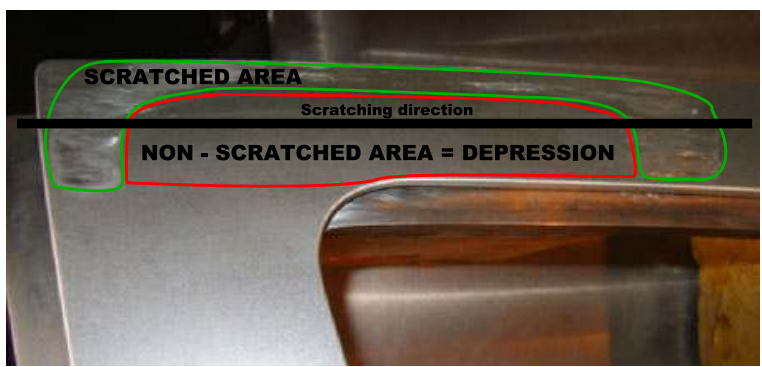

(a)

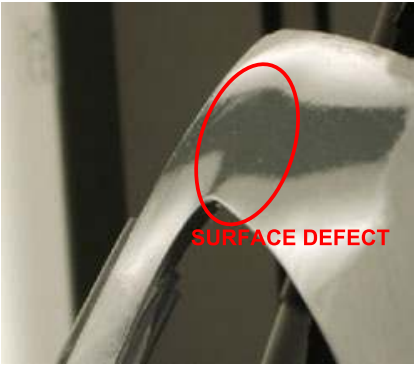

(b)

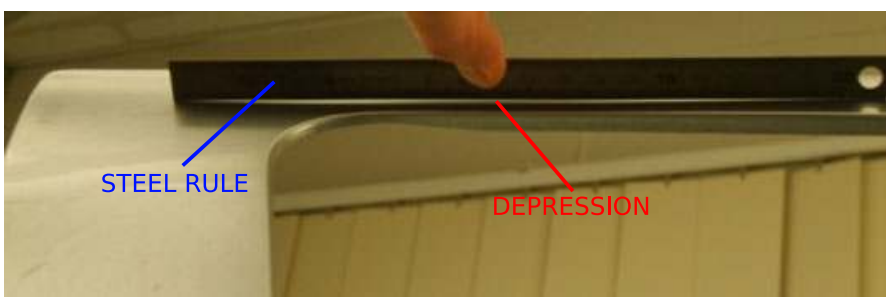

(c) 
high sampling rate of the surface geometry. The upper corner of the door has been digitalized with a stereo correlation system that uses fringe-projection [9] and compared with the CAD geometry. The several digitalizations result in a CAD surface that has been processed by two different methods.

The first one requires that the approximative area of the defect is already located, which can be achieved by applying a directional scale factor on the measured surface along its normal direction. The digitalized surface is imported in a CAD software (Catia V5) and parallel lines are projected on the surface in the defect area. Then, straight lines, which are equivalent to a virtual steel ruler, are drawn between the extremities of the defect along these projected lines. Finally the distance between the straight lines and the surface is measured and plotted as magnified vectors. It exhibits a depression with a depth of $0.42 \mathrm{~mm}$ and aproximate length and width of respectively $100 \mathrm{~mm}$ and $30 \mathrm{~mm}$ (Fig. 2).

This method allows for an easy visualization of a surface defect shape, but it mainly quantifies its maximum depth and the definition of the straight line extremities are user-dependent. To obtain a better quantification of the defect and allow for comparisons, both CAD and digitalized surfaces have been imported into the NXT Defect Evaluator post processor developed by the Japanese company M\&M Research Inc. Twelve parallel XZ planes have been defined according to Fig. 3 and profiles have been extracted (Fig. 4) showing a defect geometry of $0.4 \mathrm{~mm}$ depth, $160 \mathrm{~mm}$ length and $25 \mathrm{~mm}$ width. By comparing the $\mathrm{Y}=25 \mathrm{~mm}$ measured profile with the CAD reference one, it can be seen that according to the steel ruler method, the surface defect presents a depth of $0.4 \mathrm{~mm}$, but if the deviation from the CAD surface is considered, it leads to a depth of $0.7 \mathrm{~mm}$ for similar length and width.

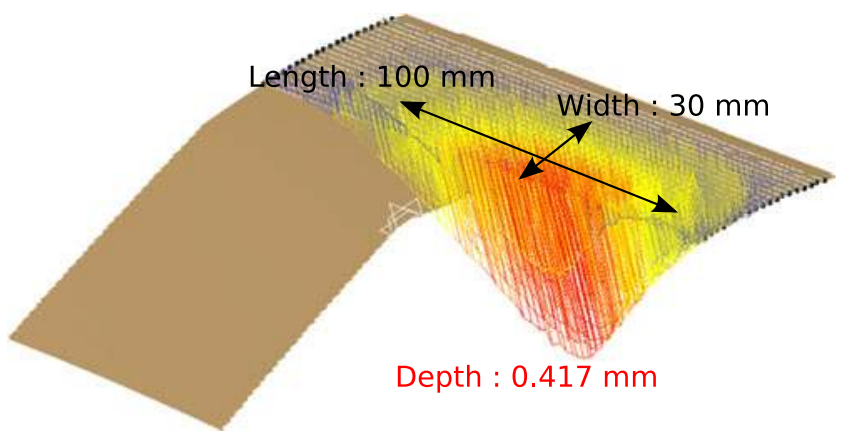

Fig. 2 Estimation of the surface defect size by drawing straight lines on the surface and measuring the gap between the lines and the effective surface

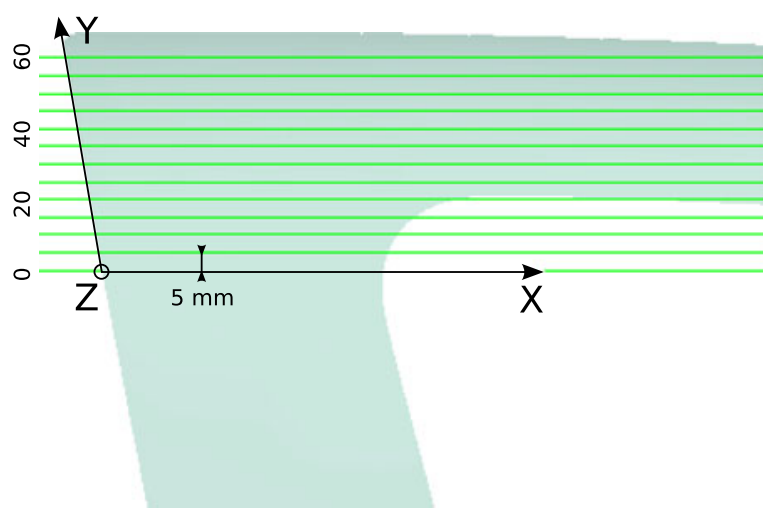

Fig. 3 Definition of the profiles on the upper corner surface

\section{Simplified geometry}

In addition to the industrial part, a specific flanging device has been designed to reproduce this kind of defect on a simplified planar L-shaped geometry. It is settled on a BUP200 (ZwickRoell) drawing machine. Its geometrical features and default values are summarized in Fig. 5. The samples are obtained from cold rolled sheets by laser cutting.

The tested material is a $0.6 \mathrm{~mm}$ thick dual-phase DP500 steel. The die-punch clearance of $0.67 \mathrm{~mm}$ leads to a $10 \%$ clearance between the blank and the tools. A constant blank-holder force of $19 \mathrm{kN}$ is applied during the test, leading to an average pressure of $3 \mathrm{MPa}$. The force-displacement curves are obtained by subtracting the punch reaction force of a test without blank so as to eliminate the contribution of the friction between the tools. The reproducibility is checked by performing

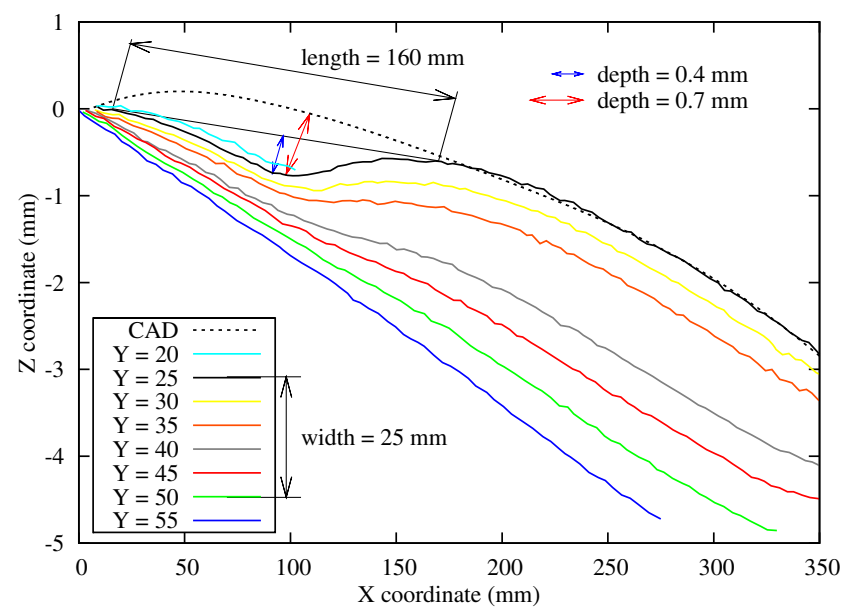

Fig. 4 Profiles of the Atos measurement on the upper corner surface 
Fig. 5 Geometrical features of the experimental flanging device. a Tools. b Blank

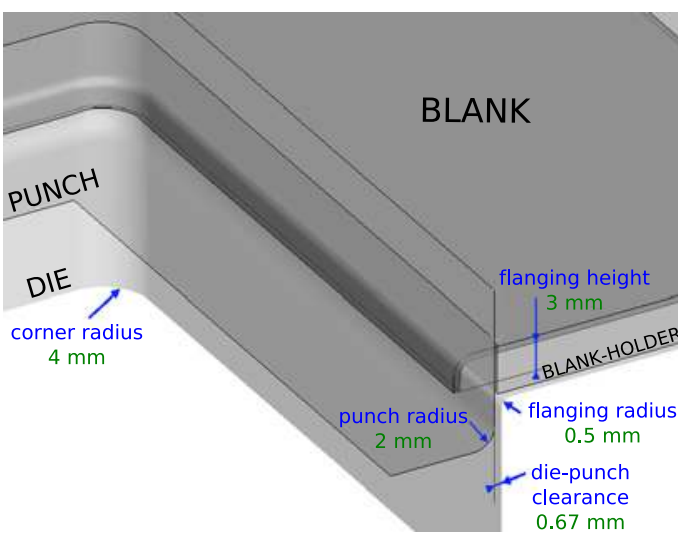

(a)

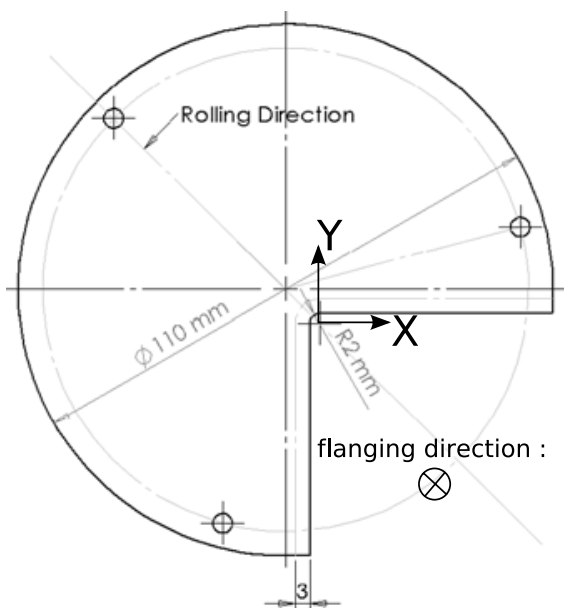

(b) three tests in the same configuration and one of them is then selected to be processed.

A selection of flanged blanks has been measured on a Brown\&Sharpe ${ }^{\circledR}$ MicroXcel pfx 4.5.4 tridimensional measuring machine with an accuracy of $3 \mu \mathrm{m}$. The blank is positioned by three holes on a dedicated setup and its surface is scanned every millimeter before and after flanging. The output is the coordinates of each scanned point. Due to the slightly non-planar surface of the virgin sample, the output Z-coordinate corresponds to the difference between the deformed and initial values. By magnifying the $\mathrm{Z}$-coordinate of the measured blank, it is observed that the defect consists of a depression near the corner radius and of two humps along the flanged edges. Figure 6 illustrates that the depression shape is not dependent on Y, contrariwise to the hump, the height of which decreases when the Y-coordinate increases. The surface defect exhibits a

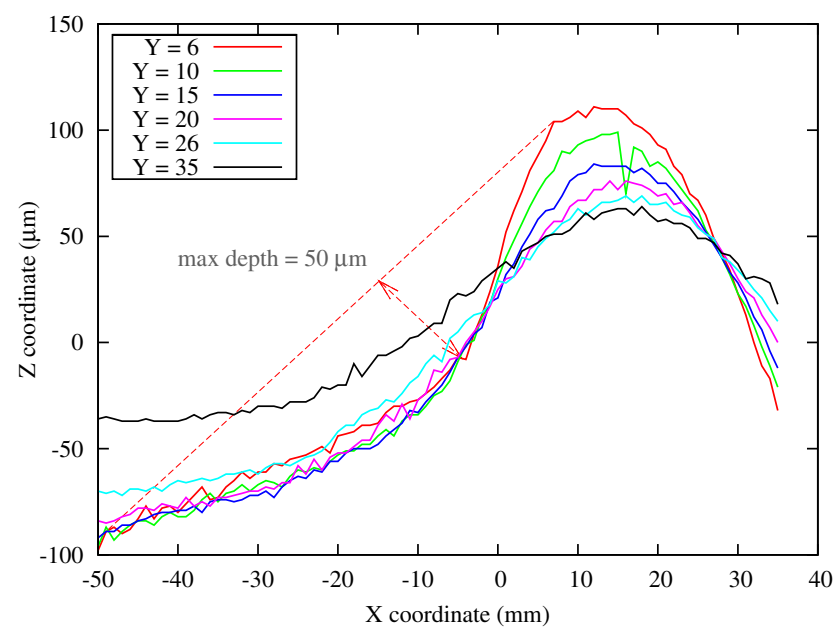

Fig. 6 Profiles along $\mathrm{X}$-axis for different $\mathrm{Y}$ values depth of $50 \mu \mathrm{m}$, and a size of $60 \mathrm{~mm}$ along the $\mathrm{X}$-axis and $30 \mathrm{~mm}$ along the $\mathrm{Y}$-axis.

Flanged blanks have also been evaluated by experts in surface-defect characterization. A surface defect was effectively found in the corner area, with a low degree of severity (indeed the lowest in the scale) that has been marked as "only visible by a specialist", but nevertheless will necessitate some modification of the geometry of the tools or process parameters to suppress it.

\section{Numerical simulation}

The aim of this section is to test the ability of a finite-element (FE) code to reproduce a surface defect with rather small dimensions, especially its depth. The mechanical behavior of the materials is modeled with an elasto-plastic law, with isotropic hardening and Hill'1948 anisotropic yield criterion. The material parameters for the bake-hardening steel of the industrial part were part of the PamStamp2G database whereas DP500 material has been characterized in order to identify the material parameters.

Industrial part

The commercial FE code PamStamp2G (ESI Group) has been used to simulate the whole outer panel geometry, from the drawing stage to the flanging operation; springback simulation is performed after each operation (stamping, trimming and flanging). The mechanical behaviour of the blank material is modeled with an elastic-plastic model with anisotropic yield and isotropic hardening. The blank is meshed using fournode shell elements with five integration points in the thickness, and the tools are discrete-rigid surfaces; 
adaptive mesh is used. Tool mesh size is of the order of $10 \mathrm{~mm}$ for the slightly curved surfaces and smaller in the radii.

\section{L-shaped part}

Simulations of the flanging of the simplified L-shaped geometry have been performed using the finite element code Abaqus, in order to test its ability to predict the occurrence and dimensions of the surface defect. The mechanical behavior of the DP500 steel has been characterized in tension, simple shear and equibiaxial expansion. Material parameters of Hill's 1948 yield criterion associated to isotropic hardening have been identified and are input data to the numerical simulation.

\section{Mechanical behavior and constitutive equations}

The mechanical behavior of DP500 steel is investigated at room temperature under three different stress and strain states, i.e. uniaxial tension, simple shear [10] (both of these tests are performed at several orientations to the rolling direction or RD) and biaxial tension. Tensile samples have a gauged area of $150 \times 20 \mathrm{~mm}^{2}$ and the local longitudinal and transverse strain distribution is measured by using a stereo-correlation technique (Table 1). The Cauchy stress is calculated from the load by assuming an isochoric plastic transformation.

Simple shear samples have a gauged area of $4.5 \times$ $50 \mathrm{~mm}^{2}$ and the local strain is measured with the same technique as the tensile tests. The shear strain $\gamma$, defined as the planar non-diagonal non-zero component of the deformation gradient tensor, is used to present the results. Biaxial tests are performed by the hydraulic bulging of circular blanks with a gauge diameter of $185 \mathrm{~mm}$ whiwh are clamped by screws between a blankholder and a matrix. A pressure sensor gives the fluid water pressure and the strain field is measured by a stereo-correlation technique.

Constitutive equations are those implemented in the standard version of the finite element code Abaqus ${ }^{\circledR}$. The elastic part of the deformation is described by Hooke's law, depending on Young's modulus measured

Table 1 Plastic anisotropy coefficients of the DP500 steel

\begin{tabular}{llllll}
\hline Material & $r_{0}$ & $r_{45}$ & $r_{90}$ & $\bar{r}$ & $\Delta r$ \\
\hline DP500 & $0.866 \pm 0.005$ & $1.040 \pm 0.01$ & $1.033 \pm 0.005$ & 0.995 & 0.09 \\
\hline
\end{tabular}

The average anisotropy coefficient $\bar{r}=\left(r_{0}+r_{90}+2 r_{45}\right) / 4$, which characterizes the normal anisotropy and the planar anisotropy, measured by the coefficient $\Delta r=\left(r_{0}+r_{90}-2 r_{45}\right) / 2$ are also given
Table 2 Material parameters for DP500, optimized to fit the experiments in uniaxial tension, simple shear and biaxial tension

\begin{tabular}{lllllll}
\hline & $\sigma_{0}(\mathrm{MPa})$ & $K_{s}(\mathrm{MPa})$ & $n_{s}$ & $F$ & $G$ & $N$ \\
\hline DP500 & 259.0 & 832.7 & 0.175 & 0.482 & 0.464 & 1.576 \\
\hline
\end{tabular}

from tensile tests $E=191 \mathrm{GPa}$, and Poisson's ratio taken equal to 0.29 , which is a reasonable value for steels.

The plastic part is derived from the yield function $\mathcal{F}$ corresponding to Hill's 1948 yield criterion, cf. Eq. 1. A scalar variable $R$ describing the isotropic hardening depends on the equivalent plastic strain $p$, defined within the work-hardening assumption. The evolution of $R$ with $p$ is chosen under an exponential form (Eq. 2).

$\mathcal{F}(\sigma, R)=\sqrt{\sigma^{d}: \mathcal{H}: \sigma^{d}}-R$

$R=K_{s}\left(\varepsilon_{0}+p\right)^{n_{s}} \quad$ with $\quad \varepsilon_{0}=\left(\frac{\sigma_{0}}{K_{s}}\right)^{1 / n_{s}}$

where $\sigma_{0}$ is the initial yield stress in $\mathrm{RD}, K_{s}$ and $n_{s}$ two material parameters, $\sigma^{d}$ the deviatoric part of the Cauchy stress tensor $\sigma$ and $\mathcal{H}$ is the fourth order Hill's tensor which takes into account the orthotropic symmetry of the material and contains the six coefficients: $F, G, H, L, M$, and $N$.

The material parameters to be identified are then: $\sigma_{0}$, $K_{s}, n_{s}$ and $F, G, N(L$ and $M)$ are kept constant and equal to 1.5 and $G+H=1)$. They are optimized by the minimization of the gap between experimental and simulated values [11] and are given in Table 2. As can be seen in Fig. 7, the stress levels are well predicted.

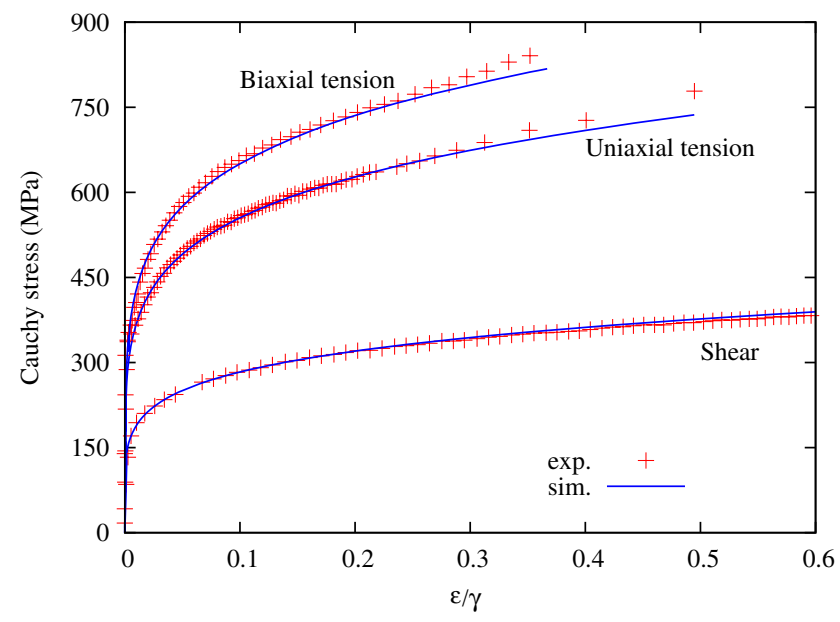

Fig. 7 Comparison of the stress levels between model predictions and experiments for uniaxial tension, simple shear, both in RD, and biaxial tension, for DP500. Similar results are found in the other orientations 


\section{Parameters}

The reference simulation corresponds to the geometry of the tools given in Fig. 5. The tools are modeled with discrete-rigid surfaces and the blank is modeled either with solid or shell elements using a reduced integration and a linear interpolation. Concerning the tool meshes, 20 nodes have been used to discretize the punch radius, 10 for the dire radius and 80 for the corner radius respectively. For planar areas of the die and the blank-holder, a maximum size of $1 \mathrm{~mm}$ has been used. The blank surface is discretized every millimeter and there are six elements in the thickness for solid elements and five integration points in the thickness for shell elements. An explicit integration scheme is used for the forming stage whereas an implicit one is used for springback. During this last stage, the blank is constrained at three points in accordance with the experimental measurements. The velocity of the punch is $16 \mathrm{~m} \cdot \mathrm{s}^{-1}$, leading to a compromise between the calculation time and the kinetic energy, that does not exceed $10 \%$ of the internal energy of the model. Interactions between the blank and the tools are modeled by a penalty method with Coulomb's friction coefficients $(f)$.

\section{Results and discussion}

As stated in previous studies, surface defects can be predicted by numerical simulation, even though there remain some geometrical differences (shape and magnitude) with experiments. However, it should be highlighted that these correlations were mainly performed in cases where the spatial location of surface defects was firstly evidenced experimentally. Therefore, a numerical criterion to detect surface defects without prior experimental knowledge is highly desirable. In this section, numerical outputs will be investigated to measure the size of the surface defects as well as to identify the factors responsible for the occurrence of surface defects.

\section{Industrial part}

After the drawing step, the mesh in the upper-corner area is decreased down to an element size of $1.3 \mathrm{~mm}$, starting from an initial value of $5.6 \mathrm{~mm}$. A depression similar to the measured surface defect appears after springback of the flanging operation. Profiles (defined on Fig. 3) at this stage are plotted in Fig. 8 and they exhibit a depression with a maximum depth of $0.8 \mathrm{~mm}$. The dimensions along the $\mathrm{X}$ - and $\mathrm{Y}$-axis are respectively $150 \mathrm{~mm}$ and $25 \mathrm{~mm}$. There is, therefore, close

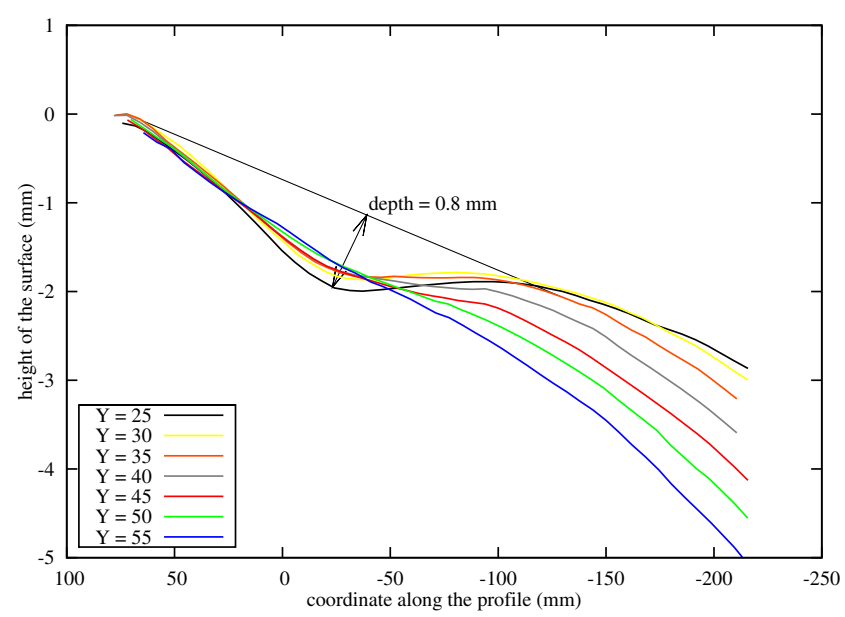

Fig. 8 Profiles after springback for the second refinement at different $\mathrm{Y}$ coordinates

correlation between experimental and predicted defect geometries.

L-shaped part

In order to reproduce numerically the load level, Coulomb's friction coefficients have been identified by fitting the experimental force vs displacement curves. To have a good representation of the experimental signal, two different friction coefficients have been used, a local one $\left(f_{l}\right)$ on the punch radius (cf. Fig. 5a), and a global one $\left(f_{g}\right)$ on all the other tool surfaces. The values $f_{l}=0.3$ and $f_{g}=0.5$ allow to fit well the experimental signal (Fig. 9). The force displacement curve is slightly higher with shell elements.

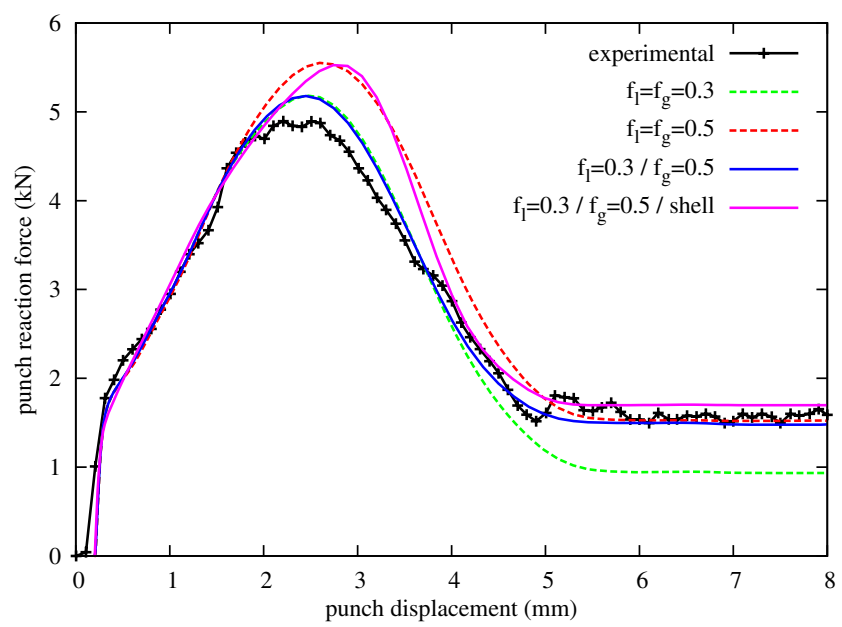

Fig. 9 Comparison of the numerical and experimental punch reaction force with different configurations of numerical friction coefficients for DP500 with a flanged length of $2.5 \mathrm{~mm}$ 
The occurrence of surface defects has been observed by plotting the $\mathrm{Z}$-coordinate along the $\mathrm{X}$-axis for several Y values after springback (Fig. 10). Rapid changes are hence highlighted in the corner vicinity, with maximum Z-values of around $60 \mu \mathrm{m}$ for positive $\mathrm{X}$-coordinate and minimum $\mathrm{Z}$-values for negative $\mathrm{X}$ coordinate. The maximum depth is $33 \mu \mathrm{m}$ for $\mathrm{Y}=$ $6 \mathrm{~mm}$ and it decreases when $\mathrm{Y}$-value increases. The order of magnitude of the dimensions along $\mathrm{X}$ - and $\mathrm{Y}$ axis is respectively $80 \mathrm{~mm}$ and $30 \mathrm{~mm}$, which is similar to the experimental data. Shell elements give a similar defect shape, but the depth is increased up to $55 \mu \mathrm{m}$ (Fig. 11). It can be noticed that the overall geometry of the sample nearby the defect area is not that well predicted compared to the experiments, in particular the $\mathrm{Z}$-coordinate decrease within the $\mathrm{X}$-coordinate range $[-50,-20]$ is not observed. It can come from a different positioning of the experimental and numerical blanks.

Moreover, it can be shown that plastic strain is quasiexclusively localized within the flanged area, in the radius. In the area of interest for the surface defect, strains remain elastic.

\section{Stress state distribution}

The stress state in the vicinity of the defect has been analyzed through the principal stress magnitude and directions. Two layers of elements are considered, located at the bottom and top surfaces and at the Ycoordinate equal to $7 \mathrm{~mm}$. Figure 12 shows that the minimal principal stress is negative in the defect area, with a maximal absolute value of $80 \mathrm{MPa}$; it decreases down to $20 \mathrm{MPa}$ at a radial distance of $7 \mathrm{~mm}$. The corresponding principal direction lies within the sheet plane,

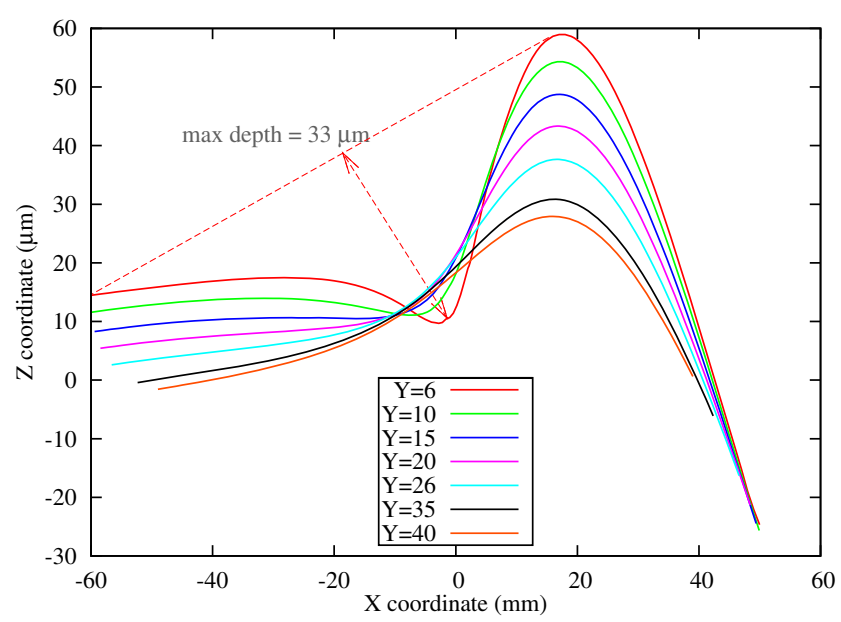

Fig. 10 Profiles along $\mathrm{X}$-axis for different $\mathrm{Y}$ values after springback. The simulation is performed with solid elements

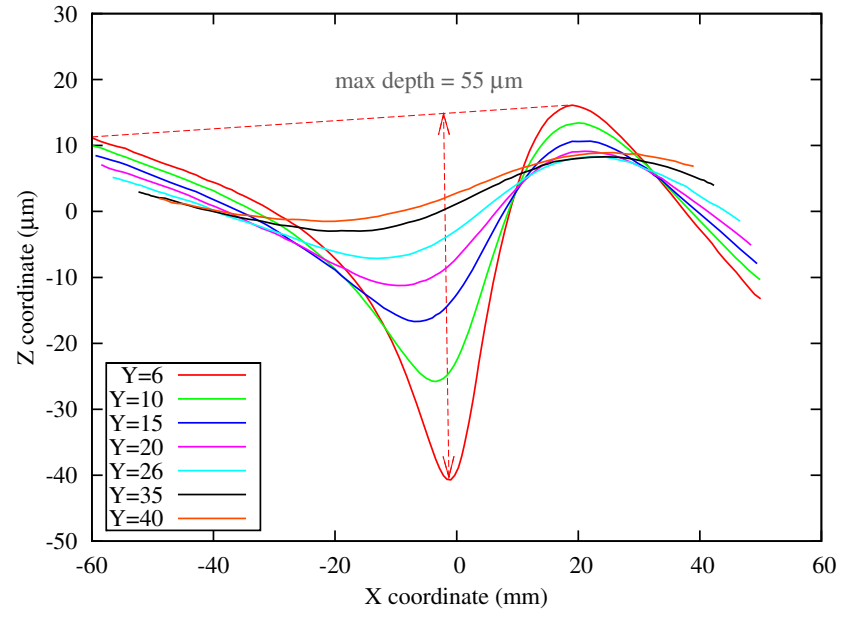

Fig. 11 Profiles along $\mathrm{X}$-axis for different $\mathrm{Y}$ values after springback. The simulation is performed with shell elements

approximately perpendicular to the rolling direction. Maximal principal stresses in the same area are positive and the corresponding directions are perpendicular to the previous ones in the sheet plane. It shows that a compressive stress is highly localized in the area of interest. The trend is similar for both the top and bottom layers.

\section{Comparison with shell elements}

Similarly, the distribution of the minimal principal stresses, but calculated with shell elements, is shown in

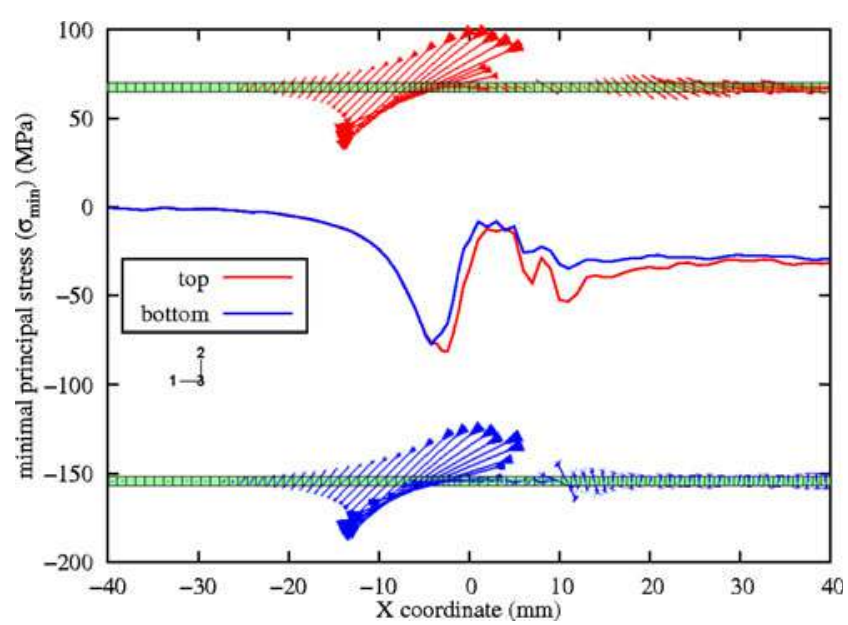

Fig. 12 Distribution of the minimum principal stress (in $\mathrm{MPa}$ ) in the bottom and top layers of the blank, at $Y=7 \mathrm{~mm}$, for solid elements. The top surface is the one in contact with the blankholder and the bottom surface with the die. The orientation of the corresponding principal direction is also given 


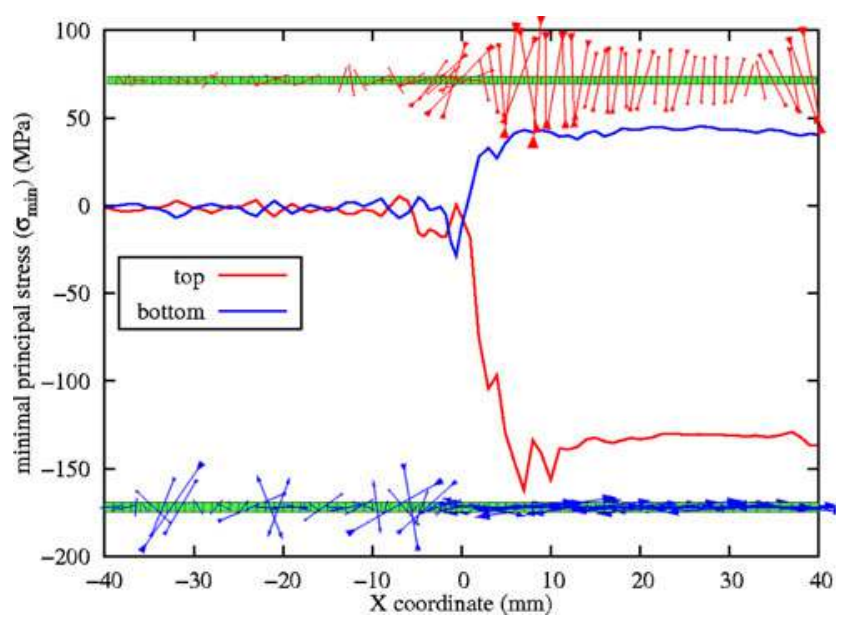

Fig. 13 Distribution of the minimum principal stress (in $\mathrm{MPa}$ ) at the bottom and top integration points for shell elements $(\mathrm{Y}=7 \mathrm{~mm})$

Fig. 13. It can be observed that the magnitude is around twice the one found with $3 \mathrm{D}$ elements and that there is a significant difference between the top and bottom integration points. The high magnitude seems to agree well with a more pronounced depth of the numerical defect. However, the friction coefficients determined in order to fit correctly the load versus displacement evolution during flanging, lead to an overestimation of the load in the case of shell elements and it certainly leads to a stress increase (in absolute value).

\section{Buckling analysis}

An area of local compressive stress exists at the end of the flanging operation, and an unstable phenomenon such as buckling may be triggered during springback. To evaluate the applicability of linear instability analyses to surface defect prediction, a numerical calculation of the buckling modes has been carried out with Abaqus, both for 3D and shell elements. The initial

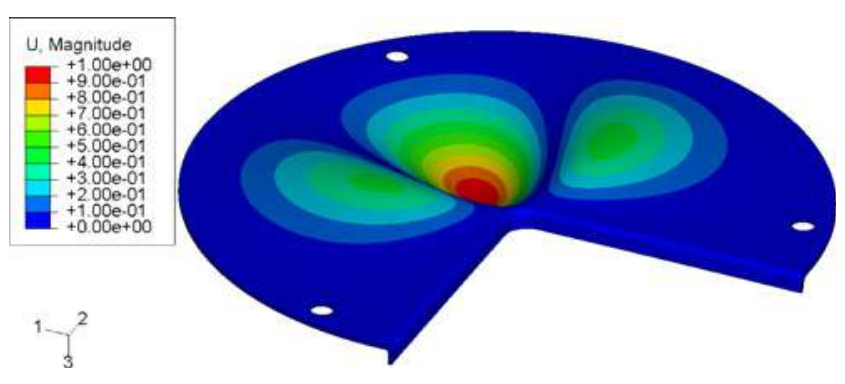

Fig. 14 Deformed shape of the blank corresponding to the third buckling mode obtained during springback geometry is the flanged blank, and the boundary conditions correspond to the displacement of the blank edges and diameter during springback, extracted from a previous implicit simulation. In this way, the area in the vicinity of the defect remains unconstrained. Figure 14 shows the deformed shape associated with the third buckling mode; it consists of one depression near the corner radius and two humps along the flanged edges, which is in accordance with the measurements. This mode corresponds to the first one with a positive eigenvalue and in accordance with the symmetry of the problem. A postbuckling analysis thus may give insights to the spatial location of the surface defects.

\section{Conclusions}

Automotive surface defects that appear in flanging have been investigated on two geometries: an upper corner of an industrial door and a simplified L-shaped part. Both geometries have been processed thoroughly with observations, measurements and numerical simulations.

The surface defect of the upper corner of the door develops during springback after the flanging stage; it was marked by technical specialists as a non-problematic one but with large dimensions. The measurements by optical fringe-projection method allowed the size of the defect to be quantified. At last, numerical simulations with the industrial code PamStamp enabled the shape to be correctly reproduced.

In the case of the simplified geometry, the surface defect has been produced by flanging DP500 blanks, with a dedicated device. The specimen geometry has been measured accurately on a tridimensional measuring machine and the geometrical features are in accordance with the surface defect dimensions given in the literature. Numerical simulations with the finite element code Abaqus reproduce the shape of the defect. In the vicinity of the defect, the minimal principal stresses are negative and the principal directions are in the sheet plane. A buckling analysis during springback gives a deformation mode exhibiting a depression near the corner radius. In this sense, it can be a predictive tool for the spatial location of surface defects, when no prior information exists, as previously stated in [12], which is the case in virtual forming.

Further work should deal with the analysis of a part exhibiting surface defects, as well as its analysis after defect-suppressive action has been taken (i.e. by directly modifying the tools), in order to validate both the geometric parameters of the defect and buckling calculation as a tool to predict their spatial locations. 
Acknowledgements The authors are grateful to the Direction Générale des Entreprises, Région Bretagne and Conseil Général du Morbihan for their financial support.

The authors would like to thank Bertrand Ipcar, engineer at the LIMATB, for performing numerical simulations with PamStamp2G.

The authors would like to thank Joëlle Garabed, Bertrand Oger and Michel Vétil from PSA Peugeot-Citroën and Yann Macé from ENS Cachan for their expertise on the industrial case. The authors would like to thank Mr. N. Mori, General Manager of M\&M Research Inc. for allowing the use of NXT Defect Evaluator software.

\section{References}

1. Banu M, Takamura M, Hama T, Naidim O, Teodosiu C, Makinouchi A (2006) Simulation of springback and wrinkling in stamping of a dual phase steel rail-shaped part. J Mater Process Technol 173:178-184

2. Kukumura M, Yamasaki Y, Inage D, Fujita T (2004) Finite element simulation of surface defects in the automobile door outer panel. In: Ghosh S, Castro JC, Lee JK (eds) CP7712 materials processing and design: modeling, simulation and applications NUMIFORM 2004, pp 1917-1922

3. Park CD, Chung WJ, Kim BM (2007) A numerical and experimental study of surface deflections in automobile exterior panels. J Mater Process Technol 187-188:99-102
4. Le Port A, Thuillier S, Manach PY, Garabed J (2008) Experimental and numerical characterization of the surface defects of an automotive door. In: Hora P (ed) Numisheet 2008, pp 773-778

5. Andersson A (2005) Evaluation and visualization of surface defects-a numerical and experimental study on sheet-metal part. In: Smith LM, Pourboghrat F, Yoon JW, Stoughton TB (eds) CP778 volume a numisheet 2005, pp 113-118

6. Andersson A (2009) Evaluation and visualisation of surface defects on auto-body panels. J Mater Process Technol 209:821-837

7. Muderrisoglu A, Murata M, Ahmetoglu MA, Kinzel G, Altan T (1996) Bending, flanging, and hemming of aluminium sheet-an experimental study. J Mater Process Technol 59:10-17

8. Li D, Luo Y, Peng Y, Hu P (2007) The numerical and analytical study on stretch flanging of V-shaped sheet metal. J Mater Process Technol 189:262-267

9. GOM Optical Measuring Techniques (2009) ATOS system, 3D digitizer, developed by GOM Optical Measuring Techniques. http://www.gom.com

10. Thuillier S, Manach PY (2009) Comparison of the workhardening of metallic sheets using tensile and shear strain paths. Int J Plast 25:733-751

11. Cailletaud G, Pilvin P (1994) Identification and inverse problems related to material behaviour. In: International seminar on inverse problems, Clamart, France, pp 79-86

12. Eid M (2007) Analyse du flambage des pièces embouties: application à la modélisation des défauts d'aspect. Dissertation, Ecole Polytechnique, France 